\title{
Pharmacokinetic Evaluation of Newly Developed Oral Immediate Release and Sustained Release Dosage Forms of Losartan Potassium
}

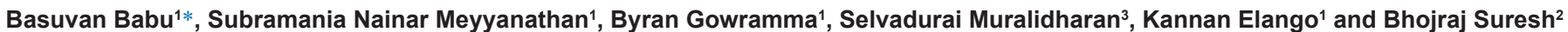 \\ ${ }^{1}$ Department of Pharmaceutical Analysis, JSS College of Pharmacy, Rocklands, Udhagamandalam - 643001 , India \\ ${ }^{2}$ JSS University, Mysore, India \\ ${ }^{3}$ Faculty of Pharmacy, AIMST University, Semeling, Bedong, Malaysia
}

\begin{abstract}
The aim of our present study is to develop oral sustained release dosage form for Losartan Potassium (SS) with wet granulation technique. Xanthan gum with additives MCC PH101 was used for the present study. The dissolution study is carried out. The studies indicated that the drug release can be modulated by varying the concentration of the polymer and fillers. The pharmacokinetic parameters including $A \cup C_{0-t}, A \cup C_{0-\infty}, C_{\max }, T_{\max }, T_{1 / 2}$, and elimination rate constant $\left(K_{e}\right)$ were determined from plasma concentration of both formulations of Immediate Release (Losartan Potassium $1.75 \mathrm{mg}$ tablets) and Sustained Release (Losartan Potassium $3.5 \mathrm{mg}$ tablets). The absorption of drug from the sustained release tablets was significantly higher than that for the reference Losartan Potassium tablet because of longer half-life and lower elimination. Different pharmacokinetic parameters including $\mathrm{AUC}_{0-1,}, \mathrm{AUC}_{0-\infty}$ $\mathrm{C}_{\max }, \mathrm{T}_{\max }, \mathrm{T}_{1 / 2}$, and $\mathrm{K}_{\mathrm{eli}}$ were determined from plasma concentration of both Sustained and Immediate release tablets.
\end{abstract}

Keywords: Losartan potassium; Immediate release; Sustained release; Xanthan Gum; Release kinetics; Pharmacokinetic parameters

\section{Introduction}

Losartan potassium (LP) is chemically 2-butyl-4-chloro-1-[p-(o$1 \mathrm{H}$-tetrazol-5ylphenyl)benzyl]imidazole-5-methanol monopotassium salt. LRT is the first of a unique class of oral antihypertensive agents referred to as angiotensin II receptor antagonists [1]

The aim of this work was to prepare matrix tablets containing Losartan Potassium, used as a model drug, and xanthan gum or karaya gum as the hydrophilic matrix to retard drug release. Xanthan was also used as a hydrophilic matrix for comparative purposes. The in vitro dissolution studies were performed on the formulation for drug release from hydrophilic matrices is known to be a complex interaction between dissolution, diffusion and erosion mechanisms. This work was an attempt to determine the relative contribution of the various drug release mechanisms from these matrix formulations. The LOD and LOQ of the present method is $2.0 \mathrm{ng} / \mathrm{ml}$ and $5.0 \mathrm{ng} / \mathrm{ml}$ and linearity was in the range of $10-150 \mathrm{ng} / \mathrm{ml}$. No method reported previsouly estimation of Losartan Potassium in plasma by using the protein precipitation (PPT) in the literature. The present work was aimed at developing a sensitive High Performance Liquid Chromatographic (HPLC) for determination of Losartan Potassium in animal plasma. The advantages of present method include single step optimized extraction procedure using PPT economic and short run time. The optimization of extraction procedure was carried out by comparing protein precipitation, and liquid-liquid extraction for recovery and interference. PPT was selected because it had obvious advantages such as shorter processing time (7 mins); lesser organic solvent consumption, fewer steps, and good plasma sample clean up. Only limited analytical methods have been developed for the determination of Losartan Potassium in biological methods [2-9]. There were no simple, rapid and reproducible methods so far reported for the estimation of by using high performance liquid chromatography of Losartan Potassium in plasma. The outcome of a study depends upon the reliability, reproducibility and sensitivity of the analytical methodology employed. Therefore, the bioanalytical method was validated in accordance with USFDA guidelines [10] prior to the initiation of the study.

\section{Materials and Methods}

\section{Materials}

Acetonitrile of HPLC grade and Methanol of HPLC grade were supplied by Merck Limited, Mumbai. Water HPLC grade obtained from Milli-Q RO system was used. Orthophosphoric acid, potassium dihydrogen orthophosphate and sodium hydroxide was procured from merck. Ethyl acetate was procured from qualigens. Working Standards of Losartan Potassium and Propyl paraben were obtained from the madras pharmaceuticals and drugs limited, chennai, Tamil Nadu, India and micro labs bangalore. Xanthan gum, polyvinyl pyrrolidine (PVP-K-30) was a gift sample from Anshul Agencies (Mumbai, India), Magnesium stearate, lactose and Talc were procured from S.D Fine Chemicals (Mumbai, India), micro crystalline cellulose Ph 101 and cross carmellose sodium.

\section{Preparation of LP (SR) tablets}

All the batches showed uniform thickness. The average percentage deviation of 20 tablets of each formula was less than $\pm 5 \%$ and hence all formulations passed the test for uniformity of weight as per official requirements (Pharmacopoeia of India 1996). Good uniformity content was found among IR and different batches of SR tablets. Another measure of tablets strength is friability. In the present study, the percentage friability for all the formulations was below $1 \%$, indicating that the friability is within the prescribed limits. All the

*Corresponding author: Basuvan Babu, JSS College of pharmacy, Off campus JSS University, Mysore, Rocklands, Udhagamandalam -643001, Tamilnadu, India Tel: +91-423-2443393; Fax: +91-423-2442937; E-mail: thammababu@gmail.com

Received October 16, 2012; Accepted October 27, 2012; Published October 29, 2012

Citation: Babu B, Meyyanathan SN, Gowramma B, Muralidharan S, Elango K, et al. (2012) Pharmacokinetic Evaluation of Newly Developed Oral Immediate Release and Sustained Release Dosage Forms of Losartan Potassium. J Bioequiv Availab 4: 121-127. doi:10.4172/jbb.1000124

Copyright: (c) 2012 Babu B, et al. This is an open-access article distributed unde the terms of the Creative Commons Attribution License, which permits unrestricted use, distribution, and reproduction in any medium, provided the original author and source are credited. 
Citation: Babu B, Meyyanathan SN, Gowramma B, Muralidharan S, Elango K, et al. (2012) Pharmacokinetic Evaluation of Newly Developed Oral Immediate Release and Sustained Release Dosage Forms of Losartan Potassium. J Bioequiv Availab 4: 121-127. doi:10.4172/jbb.1000124

tablets formulations showed acceptable pharmacotechnical properties and complied with the specifications for weight variation, drug content, hardness and friability. For the preliminary work batches of 100 tablets were used. Batches were prepared for each formulation and the compositions of different batches of LP SR tablets are given in table 1.

\section{Development of losartan potassium sustained release (SR) tablets}

Losartan potassium SR tablets were prepared by direct compression method. All the composition, with the exception of magnesium stearate and talc were thoroughly mixed in a tumbling mixer by geometric method for $30 \mathrm{~min}$ and were lubricated with a mixture of magnesium stearate and talc $(2: 1)$. The Losartan potassium tablets were prepared using an automatic tablet punching machine. Compression was performed with a single punch press applying a compression force of a $9 \mathrm{KN}$ (preliminary work) or $12 \mathrm{KN}$ (experimental design), equipped with a $5 \mathrm{~mm}$ concave punch. For the preliminary work, batches of 50 tablets were prepared. Each batch of experimental design consisted of 50 tablets (drug content in the tablet was $3.5 \mathrm{mg}$ ). Five batches were prepared for losartan potassium SR, each formulation and the compositions of losartan potassium SR tablets are given in table 2 . The compressed tablets were subjected to quality control analysis parameters like average weight and weight variation, thickness, diameter, drug content \& content uniformity, hardness, friability, in vitro drug release and in vivo drug release study.

\section{Development of losartan potassium immediate release (IR) tablets}

Losartan Potassium IR tablets were prepared by the wet granulation method. All the composition, with the exception of magnesium stearate, cross carmellose sodium and talc were thoroughly mixed in a tumbling mixer for $5 \mathrm{~min}$ and wetted in a mortar with isopropyl alcohol. The wet mass was sieved in (16 mesh) and granules were dried at $60^{\circ} \mathrm{C}$ for 2 hours. The dried granules were sieved in ( 22 mesh) and these granules were lubricated with a mixture of magnesium stearate and talc $(2: 1)$. The Losartan Potassium tablets were prepared using an electrically operated punching machine. Compression was performed after granulation process with a single punch press applying a compression force of a $9 \mathrm{KN}$ (preliminary work) or $12 \mathrm{KN}$ (experimental design), equipped with a $5 \mathrm{~mm}$ concave punch. For the preliminary work, batches of 50 tablets were prepared. Each batch of experimental design consisted of 50 tablets (drug content in the tablet was $1.75 \mathrm{mg}$ ). One batch was prepared for Losartan Potassium IR and the compositions of losartan potassium IR tablets are given in table 1 . The compressed tablets were evaluated for average weight and weight variation, thickness, diameter, drug content \& content uniformity, hardness, friability and in vitro drug release.

\section{Granule properties}

The granulation properties examined included the following: loss on drying, particle size distribution (after drying and final blend), geometric mean diameter, bulk and tap densities and percent compres suability (Carr's index).

\section{Standard physical test of tablets}

The physical testing of tablets was performed after a relaxation period of at least $24 \mathrm{~h}$ stored at the same $\mathrm{RH}$ conditions than powders. The tablet average weight and the standard deviation (SD) were obtained from 20 individually weighed (Sartorius analytical balance, Mumbai) tablets according to USP. The thickness of ten tablets was measured individually using an electronic micrometer (Mitutoyo MDC-M293, Tokyo, Japan). The resistance to crushing of ten tablets was determined by diametral loading with a Monsanto hardness tester. Tablet friability was calculated as the percentage weight loss on using 20 tablets, 4 min at 25 r.p.m. in an (Electrolab Mumbai) friability tester.

\section{Drug content}

The drug content in the formulations of Losartan Potassium was estimated by the above mentioned optimized procedure. The retention times of Losartan Potassium and Propyl paraben were 3.7 and 4.9 min, respectively.

\section{In vitro release studies}

The release characteristics of test and reference formulations of Losartan Potassium was determined using USP XXIII dissolution apparatus (type II, paddle), at $50 \mathrm{rpm}$. The dissolution media used for Losartan Potassium was $0.1 \mathrm{~N}$ hydrochloric acid ph 1.2 and phosphate buffer $\mathrm{pH} 6.8$ containing for 24 hours maintained at $37^{\circ} \mathrm{C}$. Dissolution tests were performed on six tablets. Five $\mathrm{ml}$ of the samples were withdrawn at $0.0,0.5,1.0,1.5,2.0,2.5,3.0,4.0,6.0,8.0,10,12.0,18.0$ and 24.0 hours time intervals. Equal quantity of the dissolution medium was replaced to the dissolution jar after each sampling. The amount of the drug released was estimated by optimized and validated HPLC methods as described in section 5.2.1. Percentage drug release and cumulative release at various time intervals were calculated and compared (Figure 1).

\section{Kinetics of drug release}

The cumulative amount of Losartan Potassium released from matrix tablets at different time intervals was fitted to zero order kinetics using Least-Squares Method of analysis to find out whether the drug release from the formulations is providing a constant drug release. The correlation coefficient between the time and the cumulative amount of drug released was also calculated to find the fitness of the data to zero order kinetics. The fitness of the data to first order kinetics was assessed

\begin{tabular}{|l|l|l|l|l|l|}
\hline Fa* & $\begin{array}{l}\text { Angle of } \\
\text { Repose }\left(^{\circ}\right)^{\star *}\end{array}$ & Loose Bulk Density $\left(\mathrm{gm} / \mathrm{cm}^{3}\right)^{\star *}$ & $\begin{array}{l}\text { Tapped Bulk Density } \\
\left.\mathrm{cm}^{3}\right)^{* *}(\mathrm{gm} /\end{array}$ & $\begin{array}{l}\text { Carr's } \\
\text { Index }(\%)^{* *}\end{array}$ & $37.67 \pm 0.05$ \\
\hline F-1 & $20.12 \pm 0.35$ & $0.37 \pm 0.04$ & $0.51 \pm 0.02$ & $1.76 \pm 0.05$ & $35.37 \pm 0.07$ \\
\hline F-2 & $19.50 \pm 0.55$ & $0.52 \pm 0.07$ & $0.67 \pm 0.04$ & $39.37 \pm 0.07$ \\
\hline F-3 & $18.75 \pm 0.57$ & $0.26 \pm 0.05$ & $0.42 \pm 0.07$ & $1.65 \pm 0.03$ & $1.45 \pm 0.03$ \\
\hline F-4 & $22.89 \pm 0.57$ & $0.34 \pm 0.04$ & $0.49 \pm 0.03$ & $1.45 \pm 0.07$ & $40.78 \pm 0.04$ \\
\hline F-5 & $23.97 \pm 0.45$ & $0.57 \pm 0.03$ & $0.73 \pm 0.03$ & $41.57 \pm 0.07$ \\
\hline
\end{tabular}

aCode of formulations, 'boose Bulk Density, 'Tapped Bulk Density.

${ }^{*} \mathrm{Fa}-$ Code of formulations **All values represent mean \pm SD $(n=3)$

Table 1: Granule properties of the different formulations of Losartan Potassium. 
Citation: Babu B, Meyyanathan SN, Gowramma B, Muralidharan S, Elango K, et al. (2012) Pharmacokinetic Evaluation of Newly Developed Oral Immediate Release and Sustained Release Dosage Forms of Losartan Potassium. J Bioequiv Availab 4: 121-127. doi:10.4172/jbb.1000124

by determining the correlation coefficient between the time and the amount of drug to be released from the formulations. The data were also fitted to the model developed by Korsmeyer (1983) in order to find out the drug release mechanism from the formulations. The cumulative percent of drug released from the formulations was plotted against time on log-log scale, and analyzed for linearity using Least-Squares Method. Calculating correlation coefficients between time and the cumulative percent of drug released on log-log scale tested the fitness of the data (Figure 2 and 3 ).

\section{HPLC analysis of losartan potassium in dissolution fluids and matrix tablets}

The quantitative determination of Losartan Potassium was performed by HPLC. A gradient HPLC (Shimadzu HPLC Class VP series) with two LC-2010A HT VP pumps, dual wave length programmable UV/VIS Detector SPD-10A VP, CTO-10AS VP Column oven (Shimadzu), SCL-10A VP system controller (Shimadzu), a disposable guard column LC-18 (Pelliguarde, LC-18, $2 \mathrm{~cm}$, Supelco, Inc., Bellefonte, PA.) and RP C-18 $(250 \times 4.6 \mathrm{~mm}$, particle size $5 \mu)$ was used. The HPLC system was equipped with the software 'Class-VP series version 6.04 (Shimadzu)'.The mobile phase used was a mixture of Acetonitrile: Methanol: $0.1 \%$ orthophosphoric acid in the ratio of 35:40:25. The filtered mobile phase components were pumped at a

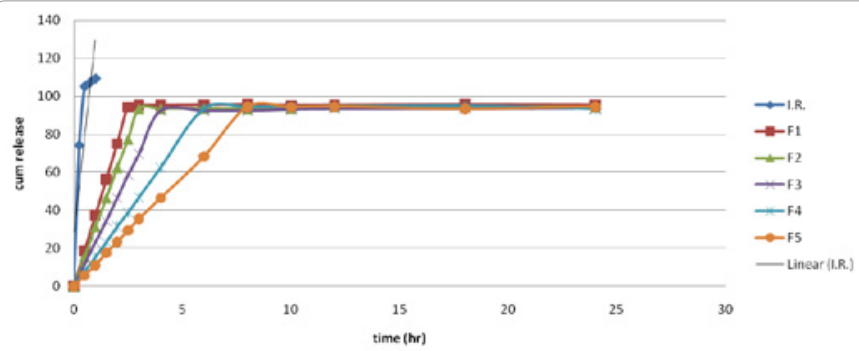

Figure 1: In vitro release profile of Losartan from Zanthan gum matrices (IR and F-1 to F-5).

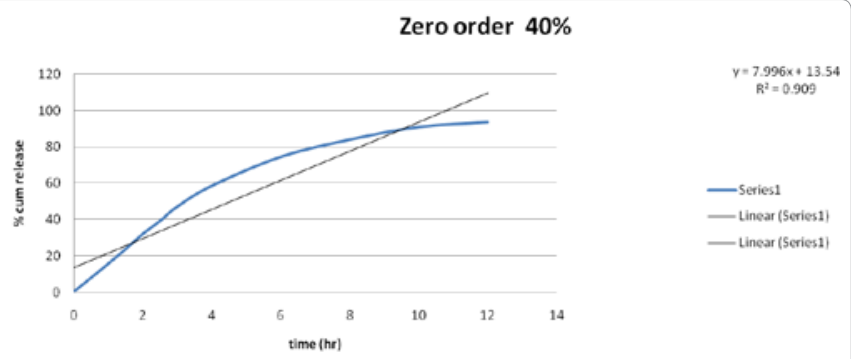

Figure 2: Zero order chart of optimized Losartan formulation (F-3).

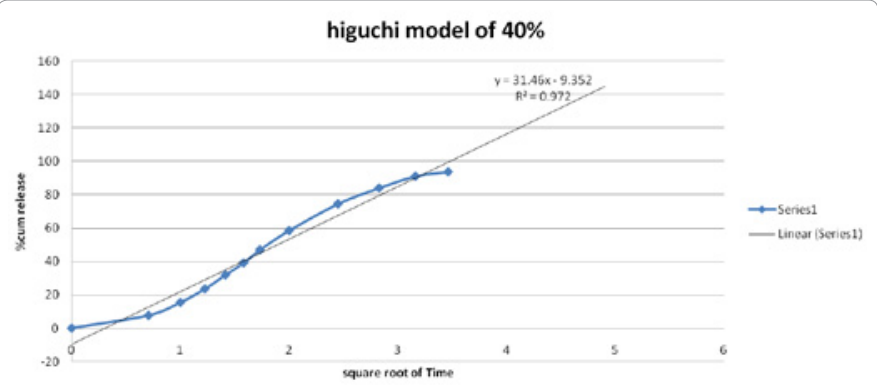

Figure 3: Higuchi chart of optimized Losartan formulation (F-3). flow rate of $1.0 \mathrm{ml} / \mathrm{min}$. The eluent was detected by UV detector at 254 $\mathrm{nm}$, and the data were acquired, stored and analyzed with the software 'Class-VP series version 6.04 (Shimadzu).

\section{In vivo studies in animal volunteers}

A single dose complete cross over method was followed to carry out bio availability studies. [JSSCP/IAEC/M.Pharm/Ph.Anal/06/2010-11] Healthy albino rabbits (2.0-2.5 kg) were obtained and kept in individual cages for 30 days prior to the study in the departmental animal house for the purpose of acclimatization. They had free access to water and food. A constant day-night cycle was maintained and the temperature of the animal room was kept constant throughout the period. Healthy over night fasted animals were used for the experiments. Zero hour fasting blood samples were withdrawn early in the morning. The animals were then divided in to 3 groups. The dose for the rabbits was selected based on the surface area ratio of rabbit and man. Group 1 (3 animals) received sustained release formulation (3.5 mg), Group 2 (2 animals) received immediate release formulation $(1.7 \mathrm{mg})$ and Group 3 ( 1 animal) was kept as control. Immediately after administration the animals were given $5 \mathrm{ml}$ of water. Blood samples $(0.5 \mathrm{ml})$ were withdrawn from the marginal ear vein at $0,0.5,1,1.5,2,2.5,3,4,6$, $8,10,12,18$ and 24 hours period using a sterilized syringe. The blood samples collected in the ria vial containing the anti coagulant $(50 \mu \mathrm{l}$ of sodium citrate) were centrifuged at $4000 \mathrm{rpm}$ for 4 minutes and the plasma samples were separated and stored at $-70^{\circ} \mathrm{C}$. The plasma samples were deproteinised by liquid liquid extraction using ethyl acetate, and the contents were vortexed for 2 minutes. It was then centrifuged at $4000 \mathrm{rpm}$ for 4 minutes and the supernatant liquid was separated and analysed. Estimation of plasma sample by HPLC was carried out using optimized chromatographic conditions mentioned in section 5.2.1 under material and methods. The standard and sample chromatograms were recorded.

\section{Pharmacokinetic analysis}

The plasma concentration of Losartan Potassium at different time intervals after oral administration of the tablet formulations to human volunteers was subjected to pharmacokinetic analysis to calculate various parameters such as maximum plasma concentration $\mathrm{C}_{\max }$ time to reach maximum concentration $\mathrm{T}_{\max }$ and area under the curve $\left(\mathrm{AUC}_{0-\mathrm{t}}\right.$ ). The values of $\mathrm{C}_{\max }$ and $\mathrm{T}_{\max }$ were directly read from the arithmetic plot of time versus plasma concentration of Losartan Potassium. The overall elimination rate constant Keli was calculated from the slope of the terminal elimination phase of a semi-logarithmic plot of concentration versus time, after subjecting it to linear regression analysis. The relative bioavailability of Losartan Potassium from matrix tablets in comparison to reference formulation (immediate release dosage form) was calculated by dividing its $\mathrm{AUC}_{0-\mathrm{t}}$ with that of immediate release tablet dosage form after applying dosage correction.

\section{Statistical analysis}

For the purpose of bioequivalence analysis $\mathrm{AUC}_{0-\mathrm{t}}, \mathrm{AUC}_{0 \text {-inf }}$ and $\mathrm{C}_{\max }$ were considered as primary variables. Bioequivalence of two formulations was assessed by means of an analysis of variance (ANOVA) for crossover design and calculating 90\% confidence interval of the ratio of test/reference using log transformed data. The formulation was considered bioequivalent when the difference between two compared parameters was found statistically insignificant $(p>0.05)$ and confidence interval for these parameters fell within $80-125 \%$. 
Citation: Babu B, Meyyanathan SN, Gowramma B, Muralidharan S, Elango K, et al. (2012) Pharmacokinetic Evaluation of Newly Developed Oral Immediate Release and Sustained Release Dosage Forms of Losartan Potassium. J Bioequiv Availab 4: 121-127. doi:10.4172/jbb.1000124

\section{Results and Discussion}

\section{Granulation properties}

Granulation is the key process in the production of many dosage forms. The sustained release tablets were prepared by wet granulation technique. Physical properties of granules such as specific surface area, shape, hardness, surface characteristics and size can significantly affect the rate of dissolution of drugs contained in a heterogenous formulation. The granules of different formulations were evaluated for angle of repose, loose bulk density, tapped bulk density and Carr's index as shown in table 1. The results of angle of repose indicate good flow properties of the granules. However, the granules had fair to poor Carr's index values. Aerosil therefore was added to dried granules prior to compression to improve the flow.

\section{Standard physical test}

The physical properties of different batches of developed tablets are given in table 2. All the batches showed uniform thickness. The average percentage deviation of 20 tablets of each formula was less than $\pm 5 \%$ and hence all formulations passed the test for uniformity of weight as per official requirements (Pharmacopoeia of India 1996). Good uniformity content was found among three different batches of tablets.

Another measure of tablets with less than $1 \% \mathrm{w} / \mathrm{w}$ of their weight is generally considered acceptable. In the present study, the percentage friability for all the formulations was below $1 \% \mathrm{w} / \mathrm{w}$, indicating that the friability is within the prescribed limits. All the tablet formulations showed acceptable pharmaceutical properties and complied with the specifications for variation, drug content, hardness and friability.

\section{Friability test}

Friability values of all the batches were less than $1 \%$. There was no accordance between hardness values and friability observations. Small values in friability imply much less friability during transportation.

\section{In vitro dissolution studies}

A suitable in vitro dissolution method serves as a valuable quality control tool to assess batch to batch release performance and to assure the physiological availability of the drug. The in vitro dissolution test is also used to guide formulation development and to monitor manufacturing process. As a regulatory test, it is used to approve minor changes in formulation, changes in the site of manufacturing and also to assess the scale-up of the bio-batch to the production batch. All the batches have shown that as the polymer concentration increases, the drug release rate decreases for Losartan Potassium. The in vitro drug release characteristics of the developed sustained release (SR) and the marketed immediate release (IR) tablets were studied. Dissolution data for all the experiments were highly reproducible and hence only the average values were plotted. The dissolution of the marketed IR tablets indicated that more than $80 \%$ of the drug is released within $1 \mathrm{~h}$, which complies with the pharmacopoeial specifications. In all the batches, we observed that as the polymer concentration increases, the drug release rate decreases (Table 3 ).

\begin{tabular}{|l|c|c|c|c|}
\hline Fa* & $\begin{array}{c}\text { Weight }(\mathrm{mg})^{* *} \\
(\mathrm{n}=20)\end{array}$ & $\begin{array}{c}\text { Thickness }(\mathrm{mm})^{* *} \\
(\mathrm{n}=5)\end{array}$ & $\begin{array}{c}\text { Hardness }\left(\mathrm{kg} / \mathrm{cm}^{2}\right)^{* *} \\
(\mathrm{n}=6)\end{array}$ & $\begin{array}{c}\text { Friability }(\%)^{* *} \\
(\mathrm{n}=6)\end{array}$ \\
\hline IR & $71.2 \pm 1.3$ & $3.23 \pm 0.9$ & $4.08 \pm 0.5$ & $0.19 \pm 0.04$ \\
\hline F-1 & $69.71 \pm 1.4$ & $3.45 \pm 0.05$ & $4.02 \pm 0.03$ & $101.05 \pm 1.4$ \\
\hline F-2 & $69.54 \pm 1.56$ & $3.35 \pm 0.04$ & $4.04 \pm 0.07$ & $0.17 \pm 0.03$ \\
\hline F-3 & $70.56 \pm 1.69$ & $3.65 \pm 0.06$ & $4.07 \pm 0.06$ & $0.13 \pm 0.02$ \\
\hline F-4 & $71.67 \pm 1.45$ & $3.65 \pm 0.08$ & $4.02 \pm 0.02$ & $0.08 \pm 0.02$ \\
\hline F-5 & $68.67 \pm 1.56$ & $3.56 \pm 0.03$ & $4.03 \pm 0.05$ & $0.07 \pm 0.01$ \\
\hline
\end{tabular}

${ }^{\mathrm{a} C o d e}$ of formulations, ${ }^{\mathrm{b}}$ Results represents the mean of replicate determination with the standard deviation given in parenthesis ${ }^{*} \mathrm{Fa}$ - Code of formulations ${ }^{* *}$ All values represent mean $\pm S D(n=3)$

Table 2: Comparison of the physical properties of the matrix tablets containing Losartan Potassium.

\begin{tabular}{|c|c|c|c|c|c|c|}
\hline \multirow{2}{*}{ Time (hours) } & \multirow[b]{2}{*}{ IR } & \multirow{2}{*}{$\mathrm{F}-1^{*}(10 \%)$} & \multirow{2}{*}{$\mathrm{F}-2^{*}(20 \%)$} & \multirow[b]{2}{*}{$\mathrm{F}-3^{*}(30 \%)$} & \multirow[b]{2}{*}{$\mathrm{F}-4^{*}(40 \%)$} & \multirow[b]{2}{*}{$\mathrm{F}-5^{*}(50 \%)$} \\
\hline & & & & & & \\
\hline 0 & 0 & 0 & 0 & 0 & 0 & 0 \\
\hline 0.25 & 74.23 & - & - & - & - & - \\
\hline 0.5 & 105.12 & 18.8 & 20 & 22.43 & 7.67 & 4.30 \\
\hline 0.75 & 107.25 & - & - & - & - & - \\
\hline 1.0 & 109.23 & 37.7 & 40.14 & 27.87 & 15.45 & 11.27 \\
\hline 1.5 & - & 56.62 & 45.66 & 55.44 & 23.5 & 18.12 \\
\hline 2.0 & - & 75.47 & 50.11 & 79.56 & 31.9 & 22.16 \\
\hline 2.5 & - & 94.45 & 60.12 & 95.17 & 39.1 & 25.29 \\
\hline 3.0 & - & 94.12 & 94.11 & 99.12 & 46.99 & 30.71 \\
\hline 4.0 & - & 94.22 & 90.46 & 93.11 & 58.8 & 66.37 \\
\hline 6.0 & - & 94.5 & 91.75 & 89.83 & 74.5 & 75.23 \\
\hline 8.0 & - & 94.40 & 91.75 & 94.52 & 84.91 & 77.39 \\
\hline 10.0 & - & - & - & - & 91 & 78.9 \\
\hline 12.0 & - & - & - & - & 93.7 & 78.8 \\
\hline 18.0 & - & - & - & - & 93.6 & 78.5 \\
\hline 24.0 & - & - & - & - & 93.7 & 78.5 \\
\hline
\end{tabular}

*All values represent mean $(n=6) \pm S D$

Table 3: In vitro release profile of Losartan Potassium from Xanthan gum matrices (IR and F-1 to F-5). 
Citation: Babu B, Meyyanathan SN, Gowramma B, Muralidharan S, Elango K, et al. (2012) Pharmacokinetic Evaluation of Newly Developed Oral Immediate Release and Sustained Release Dosage Forms of Losartan Potassium. J Bioequiv Availab 4: 121-127. doi:10.4172/jbb.1000124

\section{Kinetics of drug release}

To know the mechanism of drug release from these formulations, the data were treated according to Zero-order, first order, Higuchi and Peppas equvations that are clearly revealed. The release profile the DXI, when plotted according to Higuchi's equvation and Peppas equvation (22-25) confirm that drug release was diffusion control as evident by the values of correlation $\left(\mathrm{r}^{2}\right)$.

\section{Bioavailability studies}

The relative bioavailability of the SR $1.4 \mathrm{mg}$ tablets given daily was compared with one dose of the marketed $0.7 \mathrm{mg}$ IR tablet. The developed SR tablet produced a plasma concentration-time profile typical of the prolonged dissolution characteristic of a SR formulation, as evident from figure 4 and 5 and table 4 . The developed SR tablets demonstrated a longer time to reach a peak concentration than the marketed tablets and appeared to have more consistent over all performance.

\section{Validation of HPLC methods}

The validation parameters such as accuracy, precision (repeatability and reproducibility), linearity and range, sensitivity (limit of detection and limit of quantitation), robustness/ruggedness, stability, selectivity/ specificity and system suitability were performed.

\section{Specificity}

HPLC-UV analysis of the blank rabbit plasma samples showed the separation of Losartan potassium and propyl paraben (internal standard IS), no interference with either of these were observed. Hence the specificity of the method was established by comparison with rabbit plasma (control). Representative chromatograms of extracted blank plasma, blank plasma fortified with internal standard (IS) are shown in figure 4 and 5 indicating no interference in the blank plasma and in drug-free rabbit plasma at the retention time of 3.6 for the drug Losartan potassium and at the retention time of 4.6 for the IS.

\section{Sensitivity}

The limit of reliable quantitation was set at the concentration of the LLOQ QC, $10 \mathrm{ng} / \mathrm{ml}$ for Losartan potassium and lowest non-zero standard.

\section{Linearity}

A regression equation with a weighing factor of $1 /$ concentration $^{2}$ was judged to produce the best fit for the concentration/detector response relationship for Losartan potassium in human plasma. The linearity range for Losartan potassium was found to be 10, 20, 150, 300, $750,1000,1100$ and $1500 \mathrm{ng} / \mathrm{ml}$. Correlation coefficient $\left(\mathrm{r}^{2}\right)$ was greater than 0.99 (Figure 6).

\section{Precision}

The precision of the assay was measured by the percent coefficient

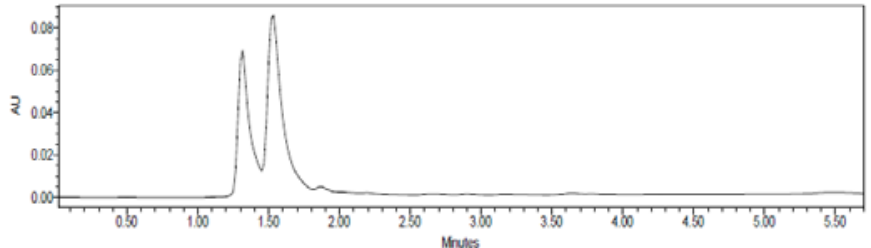

Figure 4: Typical chromatogram of blank plasma.

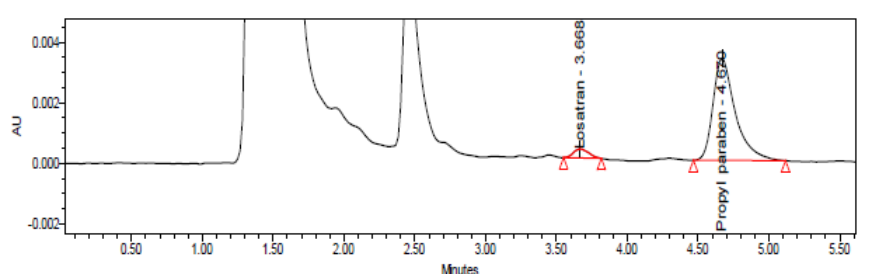

Figure 5: Typical chromatogram of sample.

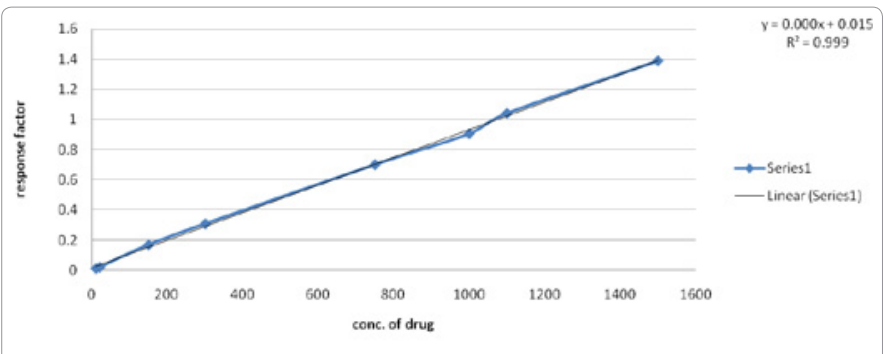

Figure 6: Calibration curve of Losartan.

of variation over the concentration range of LLOQ, low, middle and high quality control sample of Losartan potassium during the course of validation. The accuracy of the assay was defined as the absolute value of the ratio of the calculated mean values of the LLOQ, low, middle and high quality control samples to their respective nominal values, expressed as percent. The results are given in table 5 .

\section{Stability studies}

The stability studies of plasma samples spiked with selected drugs were subjected to three freeze-thaw cycles, short term stability at room temperature for 3 hours and long term stability at $-70^{\circ} \mathrm{C}$. In addition, stability of standard solutions was performed at room temperature for 6 hours and freeze condition for four weeks. The mean concentrations of the stability samples were compared to the theoretical concentrations. The results indicate that selected drugs in plasma samples can be stored for a month without degradation in frozen state. The results of short term storage at room temperature stability and freeze-thaw cycles indicate no degradation of selected drugs in plasma as well as in sample

\begin{tabular}{|c|c|c|c|c|c|}
\hline Type of formulation & $\mathrm{C}_{\max }{ }^{c}$ & $\mathrm{~T}_{\max }{ }^{c}$ & $\mathrm{AUC}_{0-\mathrm{t}}{ }^{\mathrm{c}}$ & $\mathrm{t}_{1 / 2}{ }^{\mathrm{c}}$ & $\mathrm{k}_{\mathrm{el}}{ }^{\mathrm{c}}$ \\
\hline $\mathrm{IR}^{\mathrm{a}}$ & $984.57 \pm 3.59$ & $2 \pm 2.7$ & $1951.49 \pm 34.82$ & $0.99 \pm 0.20$ & $0.70 \pm 0.021$ \\
\hline SRT $^{\mathrm{b}}$ & $1132.94 \pm 5.28$ & $3.67 \pm 3.25$ & $7647.54 \pm 256.09$ & $0.29 \pm 0.12$ & $2.52 \pm 0.010$ \\
\hline
\end{tabular}

almmediate release tablets

bSustained release tablets

${ }^{\mathrm{c}}$ Results represents the mean of replicate determination with the standard deviation given in parenthesis

Table 4: Mean pharmacokinetic profile $(\mathrm{ng} / \mathrm{ml})$ of Losartan Potassium immediate release and sustained release tablets. 
Citation: Babu B, Meyyanathan SN, Gowramma B, Muralidharan S, Elango K, et al. (2012) Pharmacokinetic Evaluation of Newly Developed Oral Immediate Release and Sustained Release Dosage Forms of Losartan Potassium. J Bioequiv Availab 4: 121-127. doi:10.4172/jbb.1000124

solution and hence plasma samples could be handled without special precautions. The results are given in table $6 \mathrm{a}$ and $6 \mathrm{~b}$.

\section{Accuracy (Recovery Study)}

Analyte recovery from a sample matrix (extraction efficiency) is a comparison of the analytical response from an amount of analyte added to that determined from the sample matrix. The detailed results are presented in table 7 . The results indicate that the recovery of Losartan potassium was consistent at all levels.

\section{Ruggedness and robustness}

The ruggedness and robustness of the methods were studied by

\begin{tabular}{|c|c|c|c|}
\hline \multicolumn{4}{|c|}{ Nominal Concentration (ng/ml): Intraday } \\
\hline S. No & LQC & MQC & HQC \\
\hline 1 & 30 & 750 & 1200 \\
\hline 2 & 29.75 & 747.83 & 1199.82 \\
\hline 3 & 32.12 & 752.97 & 1200.74 \\
\hline 4 & 28.56 & 749.42 & 1205.57 \\
\hline 5 & 29.81 & 751.63 & 1198.01 \\
\hline Mean & 30.28 & 747.12 & 1207.39 \\
\hline S.D (+/-) & 30.104 & 749.794 & 1202.306 \\
\hline C.V. (\%) & 1.293 & 2.480 & 3.987 \\
\hline \% Nominal & 9.296 & 0.331 & 0.332 \\
\hline N & 99.655 & 100.027 & 99.808 \\
\hline \multicolumn{2}{|c|}{ Table 5: Precision study for Losartan Potassium. } \\
\hline
\end{tabular}

\begin{tabular}{|l|c|c|c|}
\hline Nominal Concentration (ng/ml) & LQC & MQC & HQC \\
\hline Freeze and Thaw & 30 & 750 & 1200 \\
\hline Cycle 1 & 30.52 & 755.36 & 1186.32 \\
\hline Cycle 2 & 28.75 & 760.25 & 1206.29 \\
\hline Cycle 3 & 27.61 & 745.81 & 1189.76 \\
\hline Mean & 28.96 & 753.80 & 1194.12 \\
\hline S.D (+/-) & 1.466 & 7.344 & 10.676 \\
\hline C.V. (\%) & 5.063 & 0.974 & 0.894 \\
\hline$\%$ Nominal & 103.591 & 99.495 & 100.492 \\
\hline N & 3 & 3 & 3 \\
\hline Nominal Concentration (ng/ml) & & & \\
\hline Short Term Plasma at & LQC & MQC & HQC \\
\hline Room Temperature & 30 & 750 & 1200 \\
\hline After 1 hr & 25.92 & 740.97 & 1180.32 \\
\hline After 2 hr & 31.01 & 759.34 & 1183.29 \\
\hline After 3 hr & 25.56 & 745.86 & 1196.76 \\
\hline Mean & 27.4967 & 748.723 & 1186.79 \\
\hline S.D (+/-) & 3.048 & 9.514 & 8.761 \\
\hline C.V. (\%) & 11.085 & 1.271 & 0.738 \\
\hline$\%$ Nominal & 3 & 3 & 101.113 \\
\hline N & & & 3 \\
\hline
\end{tabular}

Table 6a: Stability study of Losartan Potassium.

\begin{tabular}{|l|c|c|c|}
\hline \multicolumn{4}{|c|}{ Nominal Concentration (ng/ml) } \\
\hline Long Term Plasma & LQC & MQC & HQC \\
\hline Sample at 70 & 30 & 750 & 1200 \\
\hline After 1 week & 27.75 & 743.44 & 1176.32 \\
\hline After 2week & 23.98 & 757.16 & 1202.29 \\
\hline After 4 week & 28.32 & 739.95 & 1185.76 \\
\hline Mean & 26.68 & 746.85 & 1188.12 \\
\hline S.D (+/-) & 2.358 & 9.098 & 13.145 \\
\hline C.V. (\%) & 8.839 & 1.218 & 1.106 \\
\hline$\%$ Nominal & 112.430 & 100.422 & 101.000 \\
\hline N & 3 & 3 & 3 \\
\hline Nominal Concentration (ng/ml) & & & \\
\hline Standard Stock solutions & LQC & MQC & HQC \\
\hline & 30 & 750 & 1200 \\
\hline After 3 hr & 29.52 & 754.32 & 1192.84 \\
\hline After 6 hr & 28.56 & 749.42 & 1205.57 \\
\hline After 4 Week & 26.72 & 749.75 & 1195.49 \\
\hline Mean & 28.2667 & 751.163 & 1197.97 \\
\hline S.D (+/-) & 1.423 & 2.739 & 6.717 \\
\hline C.V. (\%) & 5.034 & 0.365 & 0.561 \\
\hline \% Nominal & 106.132 & 99.845 & 100.170 \\
\hline N & 3 & 3 & 3 \\
\hline
\end{tabular}

Table 6b: Stability study of Losartan Potassium.

changing the experimental conditions such as operators, instruments, source of reagents and column of similar type, $\mathrm{pH}$, mobile phase ratio and flow rate.

\section{Estimation of selected drug in plasma samples}

The calibration curve samples (CC samples), quality control samples (QC samples) and plasma sample solutions were injected with the optimized \& validated chromatographic conditions and the chromatograms were recorded. The quantification of the chromatogram was performed using peak area ratios (response factor) of the drug to internal standard. The calibration curves were constructed routinely for spiked plasma containing the drug candidates and internal standard during the process of pre-study validation and in study validation. The mobile phase used for the assay provided a well defined separation between the drug, internal standard and endogenous components. The zero hour (pre dose) samples of all subjects showed no interference at retention time of both selected drugs and internal standards. The individual and mean concentrations of the drugs present in the plasma samples were calculated.

\section{In vivo data analysis}

Pharmacokinetic parameters such as peak plasma concentration $\left(\mathrm{C}_{\max }\right)$, time to peak concentration $\left(\mathrm{t}_{\max }\right)$, area under the plasma concentration-time curve $\left(\mathrm{AUC}_{0-\mathrm{t}} \& \mathrm{AUC}_{0-\infty}\right)$, elimination rate constant $\left(\mathrm{k}_{\mathrm{el}}\right)$ and elimination half-life $\left(\mathrm{t}_{1 / 2}\right)$ were calculated separately and the blood level data of selected formulations were compared. The mean pharmacokinetic profile and parameters for the sustained release (SR) test formulations and the reference formulations. There was thus a decrease in the absorption for the SR formulations when compared to the immediate release (IR) reference formulations (Figure 7).

\section{Conclusions}

The sustained release tablets of Losartan Potassium were well 
Citation: Babu B, Meyyanathan SN, Gowramma B, Muralidharan S, Elango K, et al. (2012) Pharmacokinetic Evaluation of Newly Developed Oral Immediate Release and Sustained Release Dosage Forms of Losartan Potassium. J Bioequiv Availab 4: 121-127. doi:10.4172/jbb.1000124

\begin{tabular}{|c|c|c|c|c|c|}
\hline Level & $\begin{array}{l}\text { Concentration of drug } \\
\text { added } \mathrm{ng} / \mathrm{ml}\end{array}$ & $\begin{array}{l}\text { Amount of drug recovered }(\mathrm{ng} / \mathrm{ml}) \\
\text { in plasma sample }\end{array}$ & Recovery (\%) & $\begin{array}{l}\text { Amount of Drug recovered (\%) in Mobile } \\
\text { phase }\end{array}$ & $\begin{array}{l}\text { Relative Recovery } \\
(\%)\end{array}$ \\
\hline Level-I & 30 & $28.07 \pm 5.47$ & $\begin{array}{l}\text { Mean : } 98.15 \\
\mathrm{CV}: 6.18 \\
\mathrm{~N}: 6\end{array}$ & $\begin{array}{l}\text { Mean }: 99.23 \\
\mathrm{CV}: 2.56 \\
\mathrm{~N} \quad: 6\end{array}$ & 97.48 \\
\hline Level-II & 750 & $753.21 \pm 2.20$ & $\begin{array}{l}\text { Mean : } 97.62 \\
C V: 3.89 \\
N: 6\end{array}$ & $\begin{array}{l}\text { Mean : } 102.84 \\
\mathrm{CV}: 0.35 \\
\mathrm{~N} \quad: 6\end{array}$ & 98.73 \\
\hline Level-III & 1200 & $1198.52 \pm 1.67$ & $\begin{array}{l}\text { Mean : } 101.45 \\
C V: 1.05 \\
N: 6\end{array}$ & $\begin{array}{l}\text { Mean : } 99.46 \\
\mathrm{CV}: 1.24 \\
\mathrm{~N} \quad: 6\end{array}$ & 99.12 \\
\hline
\end{tabular}

Table 7: Accuracy (Recovery Studies).

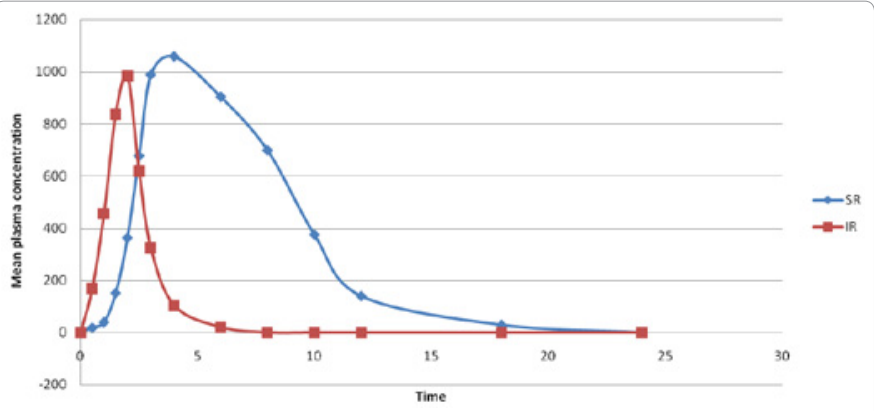

Figure 7: Mean plasma concentrations ( $\mathrm{ng} / \mathrm{ml})$ for immediate release and sustained release product of Losartan.

absorbed and the extent of absorption was higher than that of the immediate release tablet. The sustained and efficient drug delivery system developed in the present study will maintain plasma Losartan Potassium levels better, which will overcome the drawbacks associated with the conventional therapy. The statistical comparison of AUC and $\mathrm{C}_{\max }$ clearly indicated no significant difference in the two formulations of $5.0 \mathrm{mg}$ of Losartan Potassium tablets. $90 \%$ confidence interval for the mean (T/R) of $\mathrm{AUC}_{0-t}, \mathrm{AUC}_{0-\mathrm{inf}}$ and $\mathrm{C}_{\max }$ indicates that the reported values were entirely within the bioequivalence acceptance range of 80 $125 \%$ (using log transformed data). This was no significant difference in extent of absorption as assessed by measurement $\mathrm{AUC}_{0 \mathrm{t}}$. However $\mathrm{AUC}_{0-\infty}$ values for the SR tablets were higher than the marketed IR tablets indicating more efficient and controlled drug delivery, which would maintain plasma SS levels better. This was also evident by the lower elimination rate and higher $t_{1 / 2}$ Values. Hence it was concluded that formulation 'Test' and 'Reference' can be interchangeable in clinical practice.

\section{References}

1. Brenner BM, Cooper ME, De Zeeuw D, Keane WF, Mitch WE (2001) Effects of losartan on renal and cardiovascular outcomes in patients with type 2 diabetes and nephropathy. N Engl J Med 345: 861-869.

2. Bonfilio R, Tarley CR, Pereira GR, Salgado HR, de Araújo MB (2009) Multivariate optimization and validation of an analytical methodology by RPHPLC for the determination of losartan potassium in capsules. Talanta 80: 236241.

3. Zhao Z, Wang Q, Tsai EW, Qin XZ, Ip D (1999) Identification of losartan degradates in stressed tablets by LC-MS and LC-MS/MS. J Pharm Biomed Anal 20: 129-136.

4. Farthing D, Sica D, Fakhry I, Pedro A, Gehr TW (1997) Simple highperformance liquid chromatographic method for determination of losartan and E-3174 metabolite in human plasma, urine and dialysate. J Chromatogr B Biomed Sci Appl 704: 374-378.

5. Jia JY, Zhang MQ, Liu YM, Liu Y, Liu GY, et al. (2010) Pharmacokinetics and bioequivalence evaluation of two losartan potassium 50-mg tablets: A single- dose, randomized-sequence, open-label, two-way crossover study in healthy Chinese male volunteers. Clin Ther 32: 1387-1395.

6. Ritter MA, Furtek Cl, Lo MW (1997) An improved method for the simultaneous determination of losartan and its major metabolite, EXP3174, in human plasma and urine by high-performance liquid chromatography with fluorescence detection. J Pharm Biomed Anal 15: 1021-1029.

7. Prasaja B, Sasongko L, Harahap Y, Hardiyanti, Lusthom W, et al. (2009) Simultaneous quantification of losartan and active metabolite in human plasma by liquid chromatography-tandem mass spectrometry using irbesartan as internal standard. J Pharm Biomed Anal 49: 862-867.

8. Hertzog DL, McCafferty JF, Fang X, Tyrrell RJ, Reed RA (2002) Development and validation of a stability-indicating HPLC method for the simultaneous determination of Losartan potassium, hydrochlorothiazide, and their degradation products. J Pharm Biomed Anal 30: 747-760.

9. Erk N (2001) Analysis of binary mixtures of losartan potassium and hydrochlorothiazide by using high performance liquid chromatography, ratio derivative spectrophotometric and compensation technique. J Pharm Biomed Anal 24: 603-611.

10. US department of health and human services (2001) Guidance for Industry: Bioanalytical method validation. Center for Drug Evaluation and Research, Maryland. 